\title{
Incessant ventricular tachycardia
}

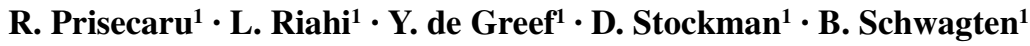

Published online: 25 August 2016

(C) The Author(s) 2016. This article is available at SpringerLink with Open Access.

\begin{abstract}
Answer
Among the side effects of adenosine, excitatory actions on ventricular automaticity enhanced by low concentrations of adenosine and the discharge of catecholamines are reported. The majority of adenosine-induced ventricular tachycardias (VTs) are rare, transient, not requiring further interventions and usually originate in the inferior left ventricular septum [1].

Since the coronary arteries showed no evidence of air embolism, thrombus or coronary atherosclerotic disease, adenosine-induced vasospasm is the most likely aetiology of the VT. The inferior ST elevation revealed in the two QRS complexes after the shock, together with the significant rise in troponin and the vasospasm depicted on angiography favour myocardial ischaemia and not a post cardioversion status [2]. The incessant character of the VT, the persistence of ST elevation and coronary vasospasm for more than just a few minutes after adenosine infusion and reversion following administration of nitrate may suggest a coronary hypersensitivity prone to develop spasm [3], such as Prinzmetal angina. Sympathetic nervous system activation is able to induce ventricular arrhythmia and coronary spasm by catecholamine release secondary to the
\end{abstract}

\footnotetext{
R. Prisecaru

ralu_prisecaru@yahoo.com

1 Cardiovascular Centrum Middelheim, Antwerpen, Belgium
}

pain triggered by the withdrawing of the transseptal sheath from the groin. This mechanism seems to be unlikely in the settings of general anaesthesia.

Although adenosine-induced incessant VT is a very rare arrhythmic complication during pulmonary vein isolation, its prompt recognition and treatment are of utmost importance. ECG monitoring is essential not only during adenosine infusion, but also during the recovery period in order to differentiate benign symptoms from serious complications such as VT and coronary spasm.

Open Access This article is distributed under the terms of the Creative Commons Attribution 4.0 International License (http:// creativecommons.org/licenses/by/4.0/), which permits unrestricted use, distribution, and reproduction in any medium, provided you give appropriate credit to the original author(s) and the source, provide a link to the Creative Commons license, and indicate if changes were made.

\section{References}

1. Tan HL, Spekhorst HH, Peters RJ, Wilde AA. Adenosine induced ventricular arrhythmias in the emergency room. Pacing Clin Electrophysiol. 2001;24:450-5.

2. Coppola G, Carità P, Corrado E, et al. ST segment elevations: Always a marker of acute myocardial infarction? Indian Heart J. 2013;65:412-23.

3. Quevedo HC, Munoz-Mendoza J, Pinto Miranda V, Sequeira RF. Coronary vasospasm while treating supraventricular tachycardia: Is adenosine really to blame? Case Rep Cardiol. 2013. Article ID 897813. doi: $10.1155 / 2013 / 897813$. 


\section{Advertisement placed here.}

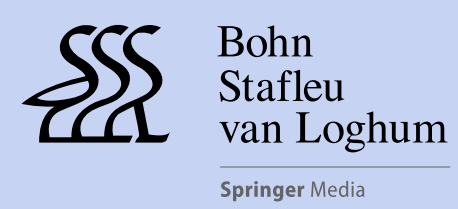

Houten 2016 